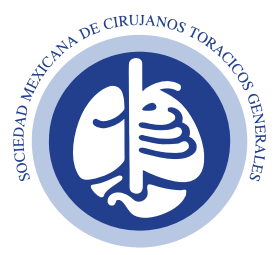

Vol. 1, Núm. 3

Septiembre-Diciembre 2020 p 79

\author{
Editorial
}

\section{La enseñanza y la pandemia}

\author{
Education and the pandemic
}

Ulises Loyola-García, ${ }^{*}$ Carlos A Olivares-Torres ${ }^{\ddagger}$

La pandemia ha traído consigo un enorme desafío de equidad educativa, la cual por el momento tendrá sus consecuencias en la formación del recurso humano en salud, en especial en la cirugía de tórax; nadie estuvo ni estamos preparados para enfrentar esta realidad, lo virtual aún no sustituye la educación hands on que requiere nuestra especialidad, por lo que debemos encarar la academia virtual, la disminución de casos o, en su defecto, la desaparición de pacientes, quienes son la base de la formación del médico residente.

Los Servicios de Cirugía de Tórax, en especial los formadores de residentes, se han convertido durante esta pandemia en unidades para tratamiento de la enfermedad del SARS-CoV-2, afectando de manera directa en el número de casos y procedimientos que se tienen que llevar a cabo para la formación de los residentes de Cirugía de Tórax en México.

Con dos unidades receptoras de residentes en el país, que son el Instituto Nacional de Enfermedades Respiratorias y el Hospital ISSEMyM de Toluca, han disminuido los casos para discutir y, por ende, tratar quirúrgicamente por la pandemia, afectando la formación del residente de cirugía de tórax; de la misma manera, se tendrá que bajar el número de casos que solicita el Consejo Nacional de Cirugía de Tórax para poder ser candidatos para certificarse en el Área de Cirugía Torácica no cardiaca.

Pero cómo resolver esto si la pandemia no tiene fin y los pacientes para realización de lobectomías por cáncer, los segmentos por enfermedad benigna, la cirugía de vía área y de esófago no llegan a los hospitales, ya sea por confinamiento o porque no se tienen los recursos para llevar a cabo las cirugías.

La pandemia ya tiene su tercer y, al parecer, cuarto respiros antes de volverse endémica, pero, ¿cómo resolver los casos? Se podría dar un año adicional para completar los requerimientos de las instituciones y del consejo, hacer rotaciones en otros hospitales que no se convirtieron en COVID, clases a distancia, cursos avalados por la Sociedad de Cirujanos Torácicos dirigidos a residentes en forma exclusiva y abrir más sedes en otras partes del país.

Mientras más pronto se controle la pandemia, podremos ofrecer más recursos y más casos para tener una adecuada educación para nuestros residentes de cirugía de tórax, fortaleciendo su enseñanza y las sedes, así como abogar por la creación de nuevos centros de cirugía de tórax formadores de residentes con un plan académico adecuado y dirigido a nuestros tiempos y a nuestra "nueva normalidad".

Citar como: Loyola-García U, Olivares-Torres CA. La enseñanza y la pandemia.

Rev Mex Cir Torac Gen. 2020; 1(3); 79. https://dx.doi.org/10.35366/101474
Carlos A Olivares-Torres

E-mail:

editor.revista@smctg.org 